

Asian-Aust. J. Anim. Sci.

Vol. 23, No. 2 : 154 - 161

February 2010

www.ajas.info

\title{
Genetic Diversity of a Chinese Native Chicken Breed, Bian Chicken, Based on Twenty-nine Microsatellite Markers
}

\author{
Fu-Xiang Ding, Gen-Xi Zhang ${ }^{1}$, Jin-Yu Wang ${ }^{1}{ }^{*}$, Yuan $\mathrm{Li}^{1}$, Li-Jun Zhang, Yue Wei ${ }^{1}$ \\ Hui-Hua Wang ${ }^{1}$, Li Zhang and Qi-Rui Hou ${ }^{1}$ \\ Institute of Animal Husbandry and Veterinary, Shanxi Academy of Agricultural Sciences, Taiyuan 030032, China
}

\begin{abstract}
The level of genetic differentiation and genetic structure in a Chinese native chicken breed, Bian chicken, and two controlled chicken populations (Jinghai chicken and Youxi chicken in China) were analysed based on 29 microsatellite markers. A total of 166 distinct alleles were observed across the 3 breeds, and 32 of these alleles (19.3\%) were unique to only 1 breed. Bian chicken carried the largest number of private alleles at 15 (46.9\%), followed by the Jinghai chicken with 12 private alleles (37.5\%). The average polymorphism information content (0.5168) and the average expected heterozygote frequency (0.5750) of the Bian chicken were the highest, and those of the Jinghai chicken were 0.4915 and 0.5505 , respectively, which were the lowest. Among 29 microsatellite loci, there were 15 highly informative loci in Bian chicken, and the other 14 were reasonably informative loci. The highly informative loci in Jinghai chicken and Youxi chicken were 17 and 14 respectively. Significant deviations from the Hardy-Weinberg equilibrium were observed at several locus-breed combinations, showing a deficit of heterozygotes in many cases. As a whole, genetic differentiation among the breeds estimated by the fixation index (Fst) were at $6.7 \%(\mathrm{p}<0.001)$. The heterozygote deficit within population (Fis) was $22.2 \%(\mathrm{p}<0.001)$, with the highest (0.249) in Bian chicken and lowest (0.159) in Youxi chicken. These results serve as an initial step in the plan for genetic characterization and conservation of the Chinese chicken genetic resource of Bian, as well as Jinghai and Youxi chickens. (Key Words : Bian Chicken, Genetic Differentiation, Microsatellite Marker, Genetic Diversity)
\end{abstract}

\section{INTRODUCTION}

Microsatellites are characterized by tandem repeats of one to six bases (Muhammet et al., 2008). Compared to other types of molecular markers, microsatellites have many advantages such as being numerous and ubiquitous throughout the genome, showing a high degree of polymorphism, and codominant inheritance (Cheng and Crittenden, 1994). Until now, microsatellite markers are the most widely used when assessing the genetic diversity, mapping of QTLs, population structure and relationship in and among various populations of indigenous and commercial chickens including Jungle Fowl (Mwacharo et al., 2007; Berthouly et al., 2008; Bodzsar et al., 2009; Heifetz et al., 2009).

Bian chicken is an eminent Chinese native dual-purpose breed, which is characterized by adaptability to coarse

\footnotetext{
* Corresponding Author: Jin-Yu Wang. Tel: +86-514-87979075, Fax: +86-514-87979075, E-mail: jywang@yzu.edu.cn

1 College of Animal Science and Technology, Yangzhou University, Yangzhou 225009, China.

Received June 11, 2009; Accepted October 9, 2009
}

feeding and frigidity, heavy egg, high-quality meat and superior adaptability. The breed is reared in the inside and outside areas of the Great Wall adjacent to the Mongolia municipality and Northern Shanxi province. The local people view the Great Wall as "Bian Wall", hence they call this breed Bian chicken (in Shanxi province it is also named Youyu chicken). Until now, only Bai et al. (2004), using 5 microsatellite markers, have assessed the genetic diversity of Bian chicken. The results showed that the genetic diversity of Bian chicken was rich, and the PIC and He were 0.6671 and 0.7457 , respectively. This chicken breed is now in serious danger of extinction because of its poor commercial performance. It is essential to use more microsatellite markers to evaluate the actual genetic diversity and to develop improvement and conservation programs so as to benefit people living in rural areas.

Because of the above reasons, we constructed a conservation population in the Institute of Animal Husbandry and Veterinary of Shanxi Academy of Agricultural Sciences. The objective of this research was to assess the genetic diversity of Bian chicken, using Jinghai chicken and Youxi chicken as controlled populations, based 
on 27 microsatellite markers recommended by the International Society for Animal Genetics and the Food and Agriculture Organization (FAO/ISAG, 2004) and on 2 unrecommended microsatellite markers. This study served as an initial step in the plan for genetic characterization and conservation of the Chinese chicken genetic resource of Bian, as well as Jinghai and Youxi chickens.

\section{MATERIALS AND METHODS}

\section{Chicken populations}

In total, 220 chickens belonging to 3 Chinese native breeds were investigated, of which two were local breeds (Bian and Youxi chicken) and the other (Jinghai chicken) was a national cultivated breed. Amongst the 220 birds, blood samples were collected from 140 Bian chickens (male:female $=1: 1$ ) belonging to a zero generation from the Institute of Animal Husbandry and Veterinary of Shanxi
Academy of Agricultural Sciences, from 50 Jinghai chickens (male:female $=1: 1$ ) from Jiangsu Jinghai Poultry Industry Group Co. Ltd., and from 30 Youxi chickens (male:female $=1: 1$ ) from the national gene bank for local chickens in the Poultry Institute, Chinese Academy of Agricultural Sciences.

Blood samples were taken from the wing vein with heparin sodium as an anticoagulant agent and stored at $-20^{\circ} \mathrm{C}$. Genomic DNA was extracted from whole blood using the phenol-chloroform method. The DNA concentrations were quantified spectrophotometrically.

\section{Microsatellite data analysis}

29 microsatellite markers distributed on 14 autosomes were chosen to evaluate the diversity. Among these, 27 markers belong to the list of microsatellite markers recommended by FAO/ISAG (2004). The names of the 29 microsatellite markers are shown in Table 1. PCR was

Table 1. Number of alleles (private alleles) for 3 chicken populations

\begin{tabular}{|c|c|c|c|c|}
\hline \multirow{2}{*}{ Loci } & \multicolumn{3}{|c|}{ Number of alleles (private alleles) } & \multirow{2}{*}{$\begin{array}{c}\text { Total number of alleles } \\
\text { (private alleles) for individual site }\end{array}$} \\
\hline & Bian chicken & Jinghai chicken & Youxi chicken & \\
\hline ADL0268 & $6(1)$ & $5(0)$ & $5(0)$ & $6(1)$ \\
\hline MCW0206 & $5(0)$ & $5(0)$ & $5(0)$ & $5(0)$ \\
\hline LEI0166 & $3(0)$ & $2(0)$ & $3(0)$ & $3(0)$ \\
\hline MCW0295 & $4(0)$ & $7(3)$ & $5(0)$ & $8(3)$ \\
\hline MCW0081 & $4(2)$ & $3(1)$ & $2(0)$ & $5(3)$ \\
\hline MCW0014 & $4(1)$ & $3(0)$ & $3(0)$ & $4(1)$ \\
\hline MCW0183 & $4(0)$ & $4(0)$ & $4(0)$ & $4(0)$ \\
\hline ADL0278 & $8(2)$ & $5(1)$ & $5(0)$ & $9(3)$ \\
\hline MCW0067 & $3(0)$ & $3(0)$ & $3(0)$ & $3(0)$ \\
\hline MCW0104 & $11(3)$ & $9(1)$ & $8(1)$ & 13(5) \\
\hline MCW0123 & $6(0)$ & $7(2)$ & $5(0)$ & $8(2)$ \\
\hline MCW0330 & $4(0)$ & $4(0)$ & $4(0)$ & $4(0)$ \\
\hline MCW0165 & $3(0)$ & $3(0)$ & $3(0)$ & $3(0)$ \\
\hline MCW0069 & $6(1)$ & $7(0)$ & $6(0)$ & $8(1)$ \\
\hline MCW0248 & $4(0)$ & $2(0)$ & $4(0)$ & $4(0)$ \\
\hline MCW0020 & $3(0)$ & $3(0)$ & $3(0)$ & $3(0)$ \\
\hline MCW0111 & $6(0)$ & $6(0)$ & $4(0)$ & $6(0)$ \\
\hline MCW0103 & $2(0)$ & $2(0)$ & $2(0)$ & $2(0)$ \\
\hline MCW0034 & $8(1)$ & $6(0)$ & $5(0)$ & $8(1)$ \\
\hline LEI0234 & $10(0)$ & $10(0)$ & $7(0)$ & $11(0)$ \\
\hline MCW0016 & $3(0)$ & $6(3)$ & $3(0)$ & $6(3)$ \\
\hline MCW0037 & $2(0)$ & $2(0)$ & $3(1)$ & $3(1)$ \\
\hline MCW0222 & $4(1)$ & $3(0)$ & $3(0)$ & $4(1)$ \\
\hline ADL0112 & $5(2)$ & $2(0)$ & $3(0)$ & $5(2)$ \\
\hline MCW0216 & $6(0)$ & $7(0)$ & $6(0)$ & $7(0)$ \\
\hline MCW0078 & $4(0)$ & $4(0)$ & $3(0)$ & $4(0)$ \\
\hline LEI0094 & $3(0)$ & $5(1)$ & $7(3)$ & $8(4)$ \\
\hline MCW0095 & $6(0)$ & $5(0)$ & $5(0)$ & $6(0)$ \\
\hline ADL0166 & $6(1)$ & $5(0)$ & $4(0)$ & $6(1)$ \\
\hline Total & 143(15) & $135(12)$ & 123(5) & $166(32)$ \\
\hline Mean & $4.93 \pm 2.20$ & $4.66 \pm 2.14$ & $4.24 \pm 1.53$ & $5.72 \pm 2.60$ \\
\hline
\end{tabular}


carried out in $25 \mu \mathrm{l}$ reactions consisting of $2 \mu \mathrm{l}$ template DNA (50 ng/ $\mu \mathrm{l}) ; 1 \mu \mathrm{l}$ of each primer $(10 \mu \mathrm{mol} / \mathrm{L}) ; 2.5 \mu \mathrm{l}$ 10×buffer; $1.5 \mu \mathrm{l} \mathrm{Mg}^{2+}(25 \mathrm{mmol} / \mathrm{L}) ; 0.2 \mu \mathrm{l}$ of Taq DNA Polymerase ( $5 \mathrm{U} / \mu \mathrm{l}) ; 2 \mu \mathrm{dNTPs}(2 \mathrm{mmol} / \mathrm{L})$; and $14.3 \mu \mathrm{l}$ sterilized water. The amplification conditions were: denaturation at $94^{\circ} \mathrm{C}$ for $6 \mathrm{~min}$, followed by 30 cycles of denaturation at $94^{\circ} \mathrm{C}$ for $30 \mathrm{~s}$, annealing at $55-60^{\circ} \mathrm{C}$ (according to different primers) for $30 \mathrm{~s}$ and extension at $72^{\circ} \mathrm{C}$ for $30 \mathrm{~s}$, and a final elongation step at $72^{\circ} \mathrm{C}$ for 10 min. The PCR products were separated on $10 \%$ undenatured polyacrylamide (29:1) gels using pBR322 DNA/BsuRI/Marker as a standard molecular size marker, and were visualized by silver nitrate staining. After imaging by the UVI gel imaging system, the sizes of alleles were determined using ONE-Dscan software (Tang, 2006).

\section{Statistical analysis}

In the analysis of within-breed genetic variability of the 220 chickens, the Microsatellite-Toolkit for Excel (Park, 2001) was used to calculate allelic frequencies and population genetic parameters such as: expected heterozygosity (He), observed heterozygosity ( $\mathrm{Ho}$ ) and the polymorphism information content (PIC).

Based on microsatellite genotyping, Wright's (1978) fixation index: Fit, Fst and Fis were estimated using the FSTAT software (Version 2.9.3.2, Goudet, 2002). Fit, Fst and Fis were the global heterozygote deficit across populations, genetic differentiation, and the heterozygote deficit within population (inbreeding coefficient), respectively. The significance of the F-statistic was determined by permutation tests with the sequential Bonferroni procedure applied over loci (Hochberg, 1988).

Pair-wise Fst values were computed for all combinations of the 3 populations using FSTAT software. Gene flow between populations was defined as the number of reproductively successful migrants per generation (Nm). The $\mathrm{Nm}$ values were calculated using the following formula: Fst $=1 /(4 \mathrm{Nm}+1)$, where $\mathrm{Nm}$ is the gene flow, and Fst is calculated as mean over loci.

A distance measure for populations diverging by drift only is based on the co-ancestry coefficient theta, and the Reynolds' distance (DR) is constructed for multiallelic, multilocus data (Reynolds et al., 1983). Reynolds' distance values between the pairs of genetic groups were calculated using the following formula: DR = - $\ln (1-\mathrm{Fst})$; where $\mathrm{DR}$ is the Reynolds' distance, and Fst is calculated as mean over loci.

\section{RESULTS}

\section{Within breed diversity}

The number of alleles for each microsatellite marker and the number of private alleles for each breed are summarized in Table 1. A total of 166 distinct alleles were detected at the 29 microsatellite markers in 220 birds. Amongst 166 distinct alleles, Bian chicken, Jinghai chicken and Youxi chicken possessed 143, 135 and 123 alleles respectively. 32 of all 166 alleles (19.3\%) were unique to only 1 breed. Bian chicken carried the largest number of private alleles at 15 (46.9\%), followed by Jinghai chicken with 12 private alleles (37.5\%). Only 5 private alleles belonged to Youxi chicken. The private alleles were observed in 15 loci of all 29 microsatellite markers (51.7\%). Across the breeds, the average number of alleles per locus was 5.72 \pm 2.60 (166/29) with the range from 2 (MCW0103) to 13 (MCW0104). The mean number of alleles in Bian chicken was 4.93 \pm 2.20 with the range from 2 (MCW0103 and MCW0037) to 11 (MCW0104). The mean number of alleles in Jinghai chicken was $4.66 \pm 2.14$ and in Youxi chicken it was $4.24 \pm 1.53$.

Polymorphism information content (PIC) and heterozygosity (He and Ho) for the 3 chicken populations are summarized in Table 2 . The average polymorphism information content (0.5168) and the average expected heterozygote frequency (0.5750) of Bian chicken were the highest, and those of Jinghai chicken were 0.4915 and 0.5505 , respectively, which were the lowest. Nevertheless, the average observed heterozygote frequency of Bian chicken was the lowest $(0.4320)$ with Youxi chicken as the highest (0.4736). As to Bian chicken, the highest values of PIC, He and Ho per locus were observed at LEI0234 (0.8400), LEI0234 (0.8600) and ADL0268 (0.9926), respectively, and the corresponding lowest were at MCW0037 (0.3001), MCW0248 (0.3626) and MCW0014 (0.1000), respectively. In terms of Jinghai chicken, the highest values of PIC and He were both observed at LEI0234 (0.7484 and 0.7822), and the lowest value of PIC and He were both observed at MCW0248 (0.1504 and 0.1655). ADL0268 showed the highest value of Ho (1.000) both in Jinghai chicken and Youxi chicken, which meant that the two chicken breeds were heterozygous at this locus. However, the value of Ho was zero at MCW0165 in Youxi chicken, which meant that at this locus all Youxi chicken were homogeneous.

\section{Breed genetic differentiation}

Genetic difference was observed (overall Fst $=0.067$, in Table 3); that is, around $6.7 \%$ of the microsatellite variation among the 3 breeds was due to breed differentiation. 24 loci contributed significantly to this differentiation. It can also be seen that the deficit of heterozygotes was very high $(0.222)(p<0.001)$. Except for 7 loci (ADL0268, LEI0166, MCW0081, MCW0103, MCW0034, ADL0112, MCW0095), the remaining loci had a significant deficit of heterozygotes. 
Table 2. Polymorphism information content (PIC), heterozygosity (He and Ho) for 3 chicken population

\begin{tabular}{|c|c|c|c|c|c|c|c|c|c|}
\hline \multirow{2}{*}{ Loci } & \multicolumn{3}{|c|}{ Bian chicken } & \multicolumn{3}{|c|}{ Jinghai chicken } & \multicolumn{3}{|c|}{ Youxi chicken } \\
\hline & PIC & $\mathrm{He}$ & Ho & PIC & $\mathrm{He}$ & Ho & PIC & $\mathrm{He}$ & Ho \\
\hline $\begin{array}{l}\text { ADL0268 } \\
\text { ADL }\end{array}$ & 0.6700 & 0.7202 & 0.9929 & 0.6708 & 0.7240 & 1.0000 & 0.7520 & 0.7994 & 1.0000 \\
\hline MCW0206 & 0.5145 & 0.5826 & 0.4714 & 0.5379 & 0.6206 & 0.4000 & 0.4804 & 0.5757 & 0.4000 \\
\hline LEI0166 & 0.3443 & 0.3871 & 0.4214 & 0.3701 & 0.4952 & 0.5800 & 0.4668 & 0.5356 & 0.6000 \\
\hline MCW0295 & 0.5772 & 0.6498 & 0.5071 & 0.5592 & 0.6160 & 0.6000 & 0.5825 & 0.6565 & 0.5667 \\
\hline MCW0081 & 0.3953 & 0.4789 & 0.5357 & 0.2399 & 0.2745 & 0.2400 & 0.3610 & 0.4808 & 0.4333 \\
\hline MCW0014 & 0.6623 & 0.7161 & 0.1000 & 0.5785 & 0.6600 & 0.1000 & 0.4345 & 0.5237 & 0.1667 \\
\hline MCW0183 & 0.3956 & 0.4249 & 0.2357 & 0.5463 & 0.6176 & 0.4400 & 0.4224 & 0.4740 & 0.4000 \\
\hline ADL0278 & 0.6872 & 0.7291 & 0.6286 & 0.4739 & 0.5160 & 0.5400 & 0.6409 & 0.7102 & 0.7667 \\
\hline MCW0067 & 0.4907 & 0.5687 & 0.4857 & 0.5122 & 0.5812 & 0.4400 & 0.4662 & 0.5492 & 0.6000 \\
\hline MCW0104 & 0.6952 & 0.7285 & 0.5500 & 0.6119 & 0.6477 & 0.5600 & 0.8136 & 0.8475 & 0.5667 \\
\hline MCW0123 & 0.4630 & 0.5214 & 0.3286 & 0.6537 & 0.7059 & 0.3200 & 0.5420 & 0.6011 & 0.2667 \\
\hline MCW0330 & 0.5996 & 0.6572 & 0.5000 & 0.6268 & 0.6954 & 0.7200 & 0.6700 & 0.7333 & 0.8000 \\
\hline MCW0165 & 0.5647 & 0.6435 & 0.1643 & 0.5023 & 0.5954 & 0.0600 & 0.2266 & 0.2441 & 0.0000 \\
\hline MCW0069 & 0.6855 & 0.7306 & 0.6071 & 0.5272 & 0.5919 & 0.5000 & 0.6534 & 0.7107 & 0.5000 \\
\hline MCW0248 & 0.3348 & 0.3626 & 0.2286 & 0.1504 & 0.1655 & 0.1400 & 0.1243 & 0.1294 & 0.1000 \\
\hline MCW0020 & 0.4380 & 0.5284 & 0.3429 & 0.2756 & 0.2992 & 0.3000 & 0.4453 & 0.5418 & 0.4333 \\
\hline MCW0111 & 0.5807 & 0.6482 & 0.4786 & 0.7319 & 0.7745 & 0.7400 & 0.5254 & 0.6096 & 0.6333 \\
\hline MCW0103 & 0.3708 & 0.4935 & 0.5429 & 0.3750 & 0.5051 & 0.4000 & 0.3566 & 0.4723 & 0.5333 \\
\hline MCW0034 & 0.6709 & 0.7059 & 0.6500 & 0.7141 & 0.7626 & 0.8000 & 0.6165 & 0.6785 & 0.5667 \\
\hline LEI0234 & 0.8400 & 0.8600 & 0.4265 & 0.7484 & 0.7822 & 0.6200 & 0.6916 & 0.7429 & 0.5667 \\
\hline MCW0016 & 0.5302 & 0.6024 & 0.4000 & 0.6971 & 0.7485 & 0.4000 & 0.5676 & 0.6537 & 0.3333 \\
\hline MCW0037 & 0.3001 & 0.3691 & 0.1143 & 0.3165 & 0.3982 & 0.3000 & 0.2676 & 0.3102 & 0.1000 \\
\hline MCW0222 & 0.5740 & 0.6472 & 0.5357 & 0.5262 & 0.5998 & 0.4600 & 0.3964 & 0.4949 & 0.4667 \\
\hline ADL0112 & 0.3262 & 0.3714 & 0.3139 & 0.2225 & 0.2576 & 0.3000 & 0.3188 & 0.3621 & 0.4333 \\
\hline MCW0216 & 0.3602 & 0.3999 & 0.2000 & 0.4651 & 0.5111 & 0.3000 & 0.4827 & 0.5158 & 0.4333 \\
\hline MCW0078 & 0.3733 & 0.4193 & 0.1429 & 0.3622 & 0.3986 & 0.0800 & 0.1991 & 0.2153 & 0.1000 \\
\hline LEI0094 & 0.4566 & 0.5516 & 0.4348 & 0.5671 & 0.6305 & 0.6200 & 0.5831 & 0.6384 & 0.5667 \\
\hline MCW0095 & 0.6019 & 0.6633 & 0.9485 & 0.4917 & 0.5830 & 0.9800 & 0.6731 & 0.7305 & 0.9333 \\
\hline ADL0166 & 0.4851 & 0.5132 & 0.2409 & 0.1994 & 0.2067 & 0.1400 & 0.6902 & 0.7508 & 0.4667 \\
\hline Mean & 0.5168 & 0.5750 & 0.4320 & 0.4915 & 0.5505 & 0.4510 & 0.4983 & 0.5617 & 0.4736 \\
\hline
\end{tabular}

PIC = Polymorphism information content; $\mathrm{He}$ = Expected heterozygosity; Ho = Observed heterozygosity.

In accordance with the analysis of existing genetic differentiation between the possible pairs of genetic groups, the Fst value showed slightly high differentiation (0.0840) between Jinghai chicken and Youxi chicken which was the highest. The lowest Fst value (0.0539) was observed between Bian and Youxi chicken. The Nm value ranged from 2.726 (between Jinghai and Youxi chicken) to 4.380 (between Bian and Youxi chicken) (Table 4). Reynolds' distance values varied between 0.0555 (Bian-Youxi chicken pair) and 0.0877 (Jinhai-Youxi chicken pair) (Table 4).

In all $87 \mathrm{HWE}$ tests (29 loci in 3 breeds), significant deviations from the HWE at the 5\% level were observed in 53 cases $(60.9 \%)$. In these deviations, $88.7 \%$ (47/53) of cases had a heterozygosity deficit. Conversely, only $11.3 \%$ of cases (6/53) had a heterozygosity excess (Table 3 and Table 5). The number of populations which deviated from the HWE at each locus ranged from 1 to 3 (Table 3). All breeds showed statistically significant deviations from the HWE at many loci. A noticeable number of deviations from the HWE were observed in Bian chicken, and only 3 loci (LEI0166, MCW0081 and MCW0103) accorded with HWE. The number of loci that accorded with HWE in Jinghai and Youxi chicken were 15 and 16 respectively (Table 5).

The heterozygote deficit within population (Fis) for the 3 chicken populations are summarized in Table 5. Comparatively, the Fis for Bian chicken was the highest (0.249) followed by Jinghai (0.182) and Youxi chicken (0.159). Many cases of Fis for Bian (22), Jinghai (13) and Youxi chicken (9) were statistically significant $(\mathrm{p}<0.01)$. In all three populations, both ADL0268 and MCW0095 showed heterozygosity excess $(\mathrm{p}<0.01)$.

\section{DISCUSSION}

PIC was an ideal index to measure the polymorphism of allele fragments. According to Botstein et al. (1980), PIC $>0.50$ indicates a highly informative locus, $0.25<$ PIC $<$ 0.50 indicates a reasonably informative locus, and 
Table 3. The results from F-statistics analysis and number of populations which deviated from Hardy-Weinberg equilibrium

\begin{tabular}{|c|c|c|c|c|}
\hline Loci & $F_{i t}$ & $F_{s t}$ & $F_{\text {is }}$ & HWE deviations \\
\hline ADL0268 & -0.343 & $0.015^{*}$ & -0.364 & 3 \\
\hline MCW0206 & $0.252 * * *$ & 0.007 & $0.247 * * *$ & 3 \\
\hline LEI0166 & -0.038 & $0.071 * * *$ & -0.117 & 0 \\
\hline MCW0295 & $0.196 * * *$ & $0.035 * * *$ & $0.167 * * *$ & 1 \\
\hline MCW0081 & $0.248 * * *$ & $0.284 * * *$ & -0.050 & 0 \\
\hline MCW0014 & $0.845^{* * *}$ & $0.031 * * *$ & $0.840^{* * *}$ & 3 \\
\hline MCW0183 & $0.394 * * *$ & $0.052 * * *$ & $0.361 * * *$ & 2 \\
\hline ADL0278 & $0.195^{* * *}$ & $0.129 * * *$ & $0.076^{*}$ & 1 \\
\hline MCW0067 & $0.160 * * *$ & $0.025^{* *}$ & $0.138 * *$ & 2 \\
\hline MCW0104 & $0.282 * * *$ & $0.058^{* * *}$ & $0.238 * * *$ & 2 \\
\hline MCW0123 & $0.462 * * *$ & $0.026 * *$ & $0.447 * * *$ & 3 \\
\hline MCW0330 & $0.217 * * *$ & $0.104 * * *$ & $0.127 * * *$ & 1 \\
\hline MCW0165 & $0.818 * * *$ & $0.102 * * *$ & $0.797 * * *$ & 3 \\
\hline MCW0069 & $0.226 * * *$ & $0.051 * * *$ & $0.185 * * *$ & 2 \\
\hline MCW0248 & $0.354 * * *$ & $0.028 * *$ & $0.335 * * *$ & 1 \\
\hline MCW0020 & $0.451 * * *$ & $0.238 * * *$ & $0.279 * * *$ & 1 \\
\hline MCW0111 & $0.181^{* * *}$ & $0.014 * * *$ & $0.169 * * *$ & 1 \\
\hline MCW0103 & -0.029 & 0.004 & -0.032 & 0 \\
\hline MCW0034 & $0.104 * *$ & $0.047 * * *$ & 0.060 & 1 \\
\hline LEI0234 & $0.438 * * *$ & $0.051 * * *$ & $0.408 * * *$ & 3 \\
\hline MCW0016 & $0.432 * * *$ & $0.064 * * *$ & $0.393 * * *$ & 3 \\
\hline MCW0037 & $0.579 * * *$ & -0.005 & $0.581^{* * *}$ & 2 \\
\hline MCW0222 & $0.230 * * *$ & $0.068 * * *$ & $0.174 * * *$ & 2 \\
\hline ADL0112 & 0.049 & 0.000 & 0.049 & 1 \\
\hline MCW0216 & $0.427 * * *$ & $0.004 *$ & $0.424 * * *$ & 2 \\
\hline MCW0078 & $0.687 * * *$ & 0.008 & $0.684^{* * *}$ & 3 \\
\hline LEI0094 & $0.259 * * *$ & $0.130 * * *$ & $0.149 * *$ & 1 \\
\hline MCW0095 & -0.430 & $0.022 * * *$ & -0.463 & 3 \\
\hline ADL0166 & $0.565 * * *$ & $0.167 * * *$ & $0.478 * * *$ & 3 \\
\hline Mean & $\begin{array}{l}0.274 \\
(0.056)^{* * *}\end{array}$ & $\begin{array}{l}0.067 \\
(0.013)^{* * *}\end{array}$ & $\begin{array}{l}0.222 \\
(0.059)^{* * *}\end{array}$ & \\
\hline
\end{tabular}

Fit = The global heterozygote deficit across three populations; Fst = Genetic differentiation; Fis = The heterozygote deficit within population (inbreeding coefficient); HWE = Number of loci not in Hardy-Weinberg equilibrium (HWE, $\mathrm{p}<0.05$ ).

Mean estimates from jack-knife over loci, standard deviations are given in parentheses; * $\mathrm{p}<0.05,{ }^{* *} \mathrm{p}<0.01,{ }^{* * *} \mathrm{p}<0.001$.

PIC $<0.25$ indicates a slightly informative locus. PIC also concerns the usability and employed frequency of a locus. In a population, the larger the PIC the more genetic information it can provide. In this study, among 29 microsatellite loci, there were 15 highly informative loci in Bian chicken, and the other 14 were reasonably informative loci. As to Jinghai chicken, the number of highly

Table 4. Nm (below diagonal) and genetic distance (above diagonal) of three chicken populations

\begin{tabular}{llll}
\hline & $\begin{array}{c}\text { Bian } \\
\text { chicken }\end{array}$ & $\begin{array}{l}\text { Jinghai } \\
\text { chicken }\end{array}$ & $\begin{array}{c}\text { Youxi } \\
\text { chicken }\end{array}$ \\
\hline Bian chicken & & 0.0736 & 0.0555 \\
Jinghai chicken & 3.271 & & 0.0877 \\
Youxi chicken & 4.380 & 2.726 & \\
\hline
\end{tabular}

polymorphic, reasonably informative, and slightly informative loci were 17, 8 and 4, respectively. There were 14 highly informative and 12 reasonably informative loci in Youxi chicken, and the other 3 loci were slightly informative. Among breeds, the average PIC values in Bian, Jianghai and Youxi chicken were 0.5168, 0.4915 and 0.4983, respectively. Therefore, these microsatellite loci chosen in this study can provide reasonable information. Compared with previous studies, the average PIC value of Bian chicken was higher than the values (0.3143-0.4918) of 11 Chinese local chickens reported by Wu et al. (2004). The average PIC value of Bian chicken was lower than the values (0.539-0.670) of 12 Chinese indigenous black-bone chicken breeds reported by Tang et al. (2005), and also lower than the value (0.6671) of Bian chicken reported by 
Table 5. Within-population heterozygote deficit (Fis) for each marker and significant levels per population

\begin{tabular}{|c|c|c|c|}
\hline \multirow{2}{*}{ Loci } & \multicolumn{3}{|c|}{ Fis } \\
\hline & Bian chicken & Jinghai chicken & Youxi chicken \\
\hline ADL0268 & $-0.380 * *$ & $-0.387 * *$ & $-0.256 * *$ \\
\hline MCW0206 & $0.191^{\# \#}$ & $0.358^{\# \#}$ & $0.309^{\#}$ \\
\hline LEI0166 & -0.089 & -0.173 & -0.123 \\
\hline MCW0295 & $0.22^{\#}$ & 0.026 & 0.139 \\
\hline MCW0081 & -0.119 & 0.127 & 0.100 \\
\hline MCW0014 & $0.861^{\# \#}$ & $0.850^{\# \#}$ & $0.685^{\# \#}$ \\
\hline MCW0183 & $0.446^{\# \#}$ & $0.290^{\# \#}$ & 0.158 \\
\hline ADL0278 & $0.138^{\# \#}$ & -0.047 & -0.081 \\
\hline MCW0067 & $0.146^{\#}$ & $0.245^{\# \#}$ & -0.094 \\
\hline MCW0104 & $0.246^{\# \#}$ & 0.137 & $0.335^{\# \#}$ \\
\hline MCW0123 & $0.371^{\# \#}$ & $0.549^{\# \#}$ & $0.561^{\# \#}$ \\
\hline MCW0330 & $0.240^{\# \#}$ & -0.036 & -0.093 \\
\hline MCW0165 & $0.745^{\# \#}$ & $0.900^{\# \#}$ & $1.000^{\# \#}$ \\
\hline MCW0069 & $0.170^{\# \#}$ & 0.157 & $0.300^{\#}$ \\
\hline MCW0248 & $0.370^{\# \#}$ & 0.155 & 0.230 \\
\hline MCW0020 & $0.352^{\# \#}$ & -0.003 & 0.203 \\
\hline MCW0111 & $0.262^{\# \#}$ & 0.045 & -0.040 \\
\hline MCW0103 & -0.100 & 0.210 & -0.132 \\
\hline MCW0034 & $0.080^{\#}$ & -0.050 & 0.167 \\
\hline LEI0234 & $0.505^{\# \#}$ & $0.209^{\# \#}$ & $0.240^{\#}$ \\
\hline MCW0016 & $0.337^{\# \#}$ & $0.468^{\# \#}$ & $0.494^{\# \#}$ \\
\hline MCW0037 & $0.691^{\# \#}$ & 0.248 & $0.681^{\# \#}$ \\
\hline MCW0222 & $0.173^{\# \#}$ & $0.235^{\#}$ & 0.058 \\
\hline ADL0112 & $0.155^{\#}$ & -0.167 & -0.201 \\
\hline MCW0216 & $0.501^{\# \#}$ & $0.416^{\# \#}$ & 0.162 \\
\hline MCW0078 & $0.660^{\# \#}$ & $0.801^{\# \#}$ & $0.540^{\#}$ \\
\hline LEI0094 & $0.212^{\# \#}$ & 0.017 & 0.114 \\
\hline MCW0095 & $-0.432 * *$ & $-0.693 * *$ & $-0.284 * *$ \\
\hline ADL0166 & $0.532^{\# \#}$ & $0.325^{\# \#}$ & $0.383^{\# \#}$ \\
\hline Mean & $0.249^{\# \#}$ & $0.182^{\# \#}$ & $0.159^{\# \#}$ \\
\hline
\end{tabular}

Fis = The heterozygote deficit within population ( inbreeding coefficient). Significant levels of deficit in heterozygotes are : ${ }^{\#}<<0.05$, ${ }^{\#} p<0.01$. Significant levels of excess in heterozygotes are : ${ }^{*} p<0.05,{ }^{* *} p<0.01$.

Bai et al. (2004) using only 5 microsatellite loci. In the latter research, blood of 53 Bian chicken (male:female = 11:42) was sampled from Qahar Youyi zhongqi of Mongolia. In our research, fertilized eggs were collected from homes of local people located on the common boundary between Youyu county of Shanxi province and Liangcheng county of Mongolia, where roads are devious and transport is not convenient. Then, these fertilized eggs were incubated in the Institute of Animal Husbandry and Veterinary of Shanxi Academy of Agricultural Sciences to construct a conservation population. In general, this difference may be due to the different genetic backgrounds of the populations studied and the different microsatellite markers employed (Shahbazi et al., 2007).
The values of PIC varied significantly at the same microsatellite locus among different chicken breeds and also in the same chicken breed among different microsatellite loci. For example, as to MCW0165, the values of PIC in Bian and Jinghai chicken were 0.5647 and 0.5023, respectively, which meant that this locus was a highly informative locus in both breeds. However, the value of PIC for MCW0165 in Youxi chicken was 0.2266, which meant that this microsatellite locus was a slightly informative locus. The highest value of PIC in Jinghai chicken was 0.7484 (LEI0234), which meant that this locus was a highly informative locus in this chicken breed, while the value of PIC for MCW0248 was 0.1504, indicating that this was a slightly informative locus in Jinghai chicken. One of the reasons for the above phenomena was that the same microsatellite locus among different chicken breeds and the different microsatellie loci in the same chicken breed underwent different selection pressure in the secular artificial selection and breeding process. However, in this study, adequate sampling of the Bian chicken was ensured by collecting fertilized Bian eggs from homes of local people located on the common boundary between Youyu county of Shanxi province and Liangcheng county of Mongoliao, and incubating these collected eggs in the Institute of Animal Husbandry and Veterinary of Shanxi Academy of Agricultural Sciences. Local people bred and reared by themselves and did not carry out specialized artificial selection, but we also can see the significant difference of the values of PIC among different microsatellite loci. This may be due to the process of adapting to the frigid and adverse circumstances under which different microsatellie loci underwent different natural selection pressure. The differences in the values of PIC among the 3 chicken breeds in this study also reflected the difference in the genetic diversity of Chinese native chicken breeds.

Heterozygosity is also known as gene diversity. Heterozygosity estimates within the population were based on a set of markers showing substantial heterogeneity in the number of alleles detected and the polymorphism information content. The use of a mixture of highly variable and less variable microsatellites should reduce the danger of overestimating genetic variability, which might occur if only highly variable loci are used (Wimmers et al., 2000). In this study, the mean $\mathrm{He}$ in Bian, Jinghai and Youxi chicken were $0.5750,0.5505$ and 0.5617 , respectively, using 29 microsatellite markers. This showed that the genetic diversity of Bian chicken is very rich. We should construct conservation centers to protect this precious breed resource. At the same time, because of the poor commercial performance of Bian chicken, we should improve the selection pressure and enhance its level of utilization, which 
implies that we should combine conventional and molecular breeding to improve production performance of Bian chicken. Athough the Jinghai chicken has undergone inbred selection for 7 generations, it also had high selection potential. The high He of Youxi chicken also meant that the conserved effect of Youxi chicken is ideal in the national gene bank for local chickens in the Poultry Institute, Chinese Academy of Agricultural Sciences. The mean He for the three breeds was quite similar to the mean value (0.551) reported for 7 Chinese local chicken breeds (Zhang et al., 2008). Hillel et al. (2003) reported that the average gene diversity within 52 populations across all 22 loci was 0.47 . The mean $\mathrm{He}(0.512)$ for the three breeds was slightly higher than that reported by Wang et al. (2003) for partial Chinese local chicken breeds using 7 microsatellite loci. The mean He recorded in this research for three breeds, however, was lower than that reported by Kong et al. (2006) for Korean native chickens (0.630) and by Shahbazi et al. (2007) for five Iranian native chickens (0.620-0.736). The variation of expected heterozygosity may be adduced to differences in location, sample size, population structure, and sources of microsatellite markers (Kaya et al., 2008).

The mean Fis for Bian, Jinghai and Youxi chicken were $0.249,0.182$ and 0.159 , respectively. These three values were higher than reported by Tadano et al. (2007) for 12 commercial chicken lines (0.000-0.141) based on 40 microsatellite loci, while lower than reported by Kaya et al. (2008) for Turkish native chickens (0.301) with 10 microsatellite loci. The high Fis for Bian chicken reminded us that in the later selection and hybridization process we should avoid full-sib and half-sib mating in order to prevent inbreeding depression.

Native breeds are considered a national asset and a key factor in creating sustainable agriculture in developing countries. Precise assessment of such native genetic resources is of great importance and could be utilized for the purpose of their conservation, management, reproduction, and exploitation (Shahbazi et al., 2007). The present analysis is of great importance because it is possibly the first genetic study of Bian chicken using many microsatellite loci. These results serve as an initial step in the plan for genetic characterization and conservation of Chinese chicken genetic resource of Bian, as well as Jinghai and Youxi chicken.

\section{ACKNOWLEDGMENTS}

The authors would like to thank Jiangsu Jinghai Poultry Industry Group Co., Ltd. and the national gene bank for local chickens in the Poultry lnstitute, Chinese Academy of Agricultural Sciences for providing blood samples. In particular, we are grateful to Dr. Wen-Bin Bao in the
College of Animal Science and Technology, Yangzhou University for teaching how to use the statistical software.

\section{REFERENCES}

Bai, W. L., R. H. Yin, S. J. Zhao, G. B. Luo, W. Q. Jiang and Y. Q. Gong. 2004. Study on genetic diversity of Bian chicken breed using microsatellite DNA markers. Chin. Poult. Sci. 33:453454.

Berthouly, C., B. Bed'Hom, M. Tixier-Boichard, C. F. Chen, Y. P. Lee, D. Laloë, H. Legros, E. Verrier and X. Rognon. 2008. Using molecular markers and multivariate methods to study the genetic diversity of local European and Asian chicken breeds. Anim. Genet. 39:121-129.

Bodzsar, N., H. Eding, T. Revay, A. Hidas and S. Weigend. 2009. Genetic diversity of Hungarian indigenous chicken breeds based on microsatellite markers. Anim. Genet. (Epub ahead of print).

Bolstein, D., R. L. White, M. Skolnik and R. W. Davis. 1980. Construction of a genetic linkage map in man using restriction fragment length polymorphisms. Am. J. Hum. Genet. 32:314331.

Cheng, H. H. and L. B. Crittenden. 1994. Microsatellite markers for genetic mapping in the chicken. Poult. Sci. 73:539-546.

FAO/MoDAD. 2004. Secondary Guidelines. Measurement of Domestic Animal Diversity (MoDAD): Recommended Microsatellite Markers. http://fao.org/dad-is

Goudet, J. 2002. FSTAT version 2.9.3.2. Department of ecology and evolution, University of Lausanne, Switzeland.

Heifetz, E. M., J. E. Fulton, N. P. O'Sullivan, J. A. Arthur, H. Cheng, J. Wang, M. Soller and J. C. Dekkers. 2009. Mapping QTL affecting resistance to Marek's disease in an F6 advanced intercross population of commercial layer chickens. BMC. Genomics 10:20.

Hillel, J., M. A. M. Groenen, M. Tixier-Boichard, A. B. Korol, L. David, V. M. Kirzhner, T. Burke, A. Barre-Dirie, R. P. M. A. Crooijmans, K. Elo, M. W. Feldman, P. J. Frei dlin, A. MÄKITANILA, T. M. Oortwijn, P. Thomson, A. Vignal, K. Wimmers and S. Weigend. 2003. Biodiversity of 52 chicken populations assessed by microsatellite typing of DNA pools. Genet. Sel. Evol. 35:533-557.

Kaya, M. and M. A. Yildiz. 2008. Genetic diversity among Turkish native chickens, Denizli and Gerze, estimated by microsatellite markers. Biochem. Genet. 46:480-491.

Kong, H. S., J. D. Oh, J. H. Lee, K. J. Jo, B. D. Sang, C. H. Choi, S. D. Kim, S. J. Lee, S. H. Yeon, G. J. Jeon and H. K. Lee. 2006. Genetic variation and relationships of Korean native chickens and foreign breeds using 15 microsatellite markers. Asian-Aust. J. Anim. Sci. 19:1546-1550.

Muhammet, K. and A. Y. Mehmet. 2008. Genetic diversity among Turkish native chickens, Denizli and Gerze, estimated by microsatellite markers. Biochem. Genet. 46:480-491.

Mwacharo, J. M., K. Nomura, H. Hanada, H. Jianlin, O. Hanotte and T. Amano. 2007. Genetic relationships among Kenyan and other East African indigenous chickens. Anim. Genet. 38:485490.

Park, S. D. E. 2001. The Excel Microsatellite Toolkit (version 3.1). Animal Genomics Laboratory, UCD, Ireland. http://animal genomics.ucd.ie/sdepark/ms-toolkit/ 
Reynolds, J., B. S. Weir and C. C. Cockerham. 1983. Estimation of the coancestry coefficient: Basis for a short-term genetic distance. Genetics 105:767-769.

Shahbazi, S., S. Z. Mirhosseini and M. N. Romanov. 2007. Genetic diversity in five Iranian native chicken populations estimated by microsatellite markers. Biochem. Genet. 45:6375.

Tadano, R., M. Nishibori, N. Nagasaka and M. Tsudzuki. 2007. Assessing genetic diversity and population structure for commercial chicken lines based on forty microsatellite analyses. Poult. Sci. 86:2301-2308.

Tang, Q. P., K. W. Chen, H. F. Li, S. J. Zhang and D. W. Zhao. 2005. Analysis of the genetic diversity of 12 Chinese indigenous black-bone chicken breeds using microsatellite marker. Acta Veterinaria et Zootechnica Sinica 36:755-760.

Tang, Q. P., K. W. Chen, Y. J. Tu, H. F. Li, S. J. Zhang and D. W. Zhao. 2006. Analysis of genetic diversity of 15 Chinese indigenous white goose breeds using 22 microsatellite loci. Journal of Nanjing Agricultural University 29:127-130.
Wang, D. Q., G. H. Chen, X. S. Wu, X. U. Zhang, K. H. Wang, R. Cheng, B. Liu, Q. Xu and Q. L. Zhou. 2003. The genetic relationship analysis among Chinese native chicken breeds by microsatellites. Journal of Yangzhou University (Agricultural and Life Sciences Edition). 24:1-6.

Wimmers, K., S. Ponsuksili, T. Hardge, A. Valle-Zarate, P. K. Mathur and P. Horst. 2000. Genetic distinctness of African, Asian and South American local Chickens. Anim. Genet. 31:159-165.

Wright, S. 1978. Variability Within and Among Natural Populations, vol 4. The University of Chicago Press, Chicago.

Wu, X. S., G. H. Chen, D. Q. Wang, X. Y. Zhang, K. H. Wang, R. Cheng, B. Liu, Q. Xu and Q. L. Zhou. 2004. Analysis of genetic relationship among Chinese native chicken breeds using microsatellites marker. Acta Genetica Sinica 31:43-50.

Zhang, X. Y., G. H. Chen, W. Han, Y. F. Zhu and J. H. Lu. 2008. Genetic differentiation and clustering analysis of 7 Chinese indigenous chicken breeds. Journal of Yunnan Agricultural University 23:225-229. 